\title{
Adaptability Discussion of Multiple-Streams Framework in Chinese Context: A Literature Review
}

\author{
Baozhen Yao ${ }^{1, *}$ Wei Cui ${ }^{1}$
}

\author{
${ }^{1}$ Beijing Normal University, Beijing, China \\ *Corresponding author. Email: cnucuiwei@163.com
}

\begin{abstract}
The differences in political and administrative system bring about differences of constituent elements evolution environment, development trend in streams of problem, policy and politic. Therefore, it brings out the necessity to discuss the theory transplantation. We try to present a detailed Chinese literature review of Multiple-streams Framework aiming to discuss the adaptability in China, and put forward the mechanism of the three streams against the background of policy structuralized. The paper will give out arguments of advantages, disadvantages and application situation of MultipleStreams Framework when looking back of different views of scholars.
\end{abstract}

\section{Keywords: Multiple-streams Framework (MSF), literature review, adaptability, Chinese context}

\section{INTRODUCTION}

In 1951, Harold Lasswell (Harold Lasswell), the founder of public policy research, published " The Policy Sciences; Recent Developments in Scope and Method." with Daniel Lemer, which defined the concept of policy science for the first time, marking the emergence of policy science in the United States. The policy science advocated by Lasswell is a new and interdisciplinary research field, which sprang up in the United States after World War II. Despite the continuous criticism as time goes by, the theory of decision-making process is still a powerful analysis tool in the field of public policy. With the emphasis on the policy process, the research no longer strictly depends on the increasing number of public administration and institutional studies in political science, as well as quasi-market research of economic preferences. As a heuristic research framework, scholars benefit from Lasswell's theory of decision-making process, and on this basis, they explore and further deepen the value of each stage, resulting in a series of new research frameworks. It makes up for the shortcomings that the stage metaphors do not adapt to empirical research and integrated policy analysis, as well as affected by dogmatism. At the same time, the emerging new public policy research framework has greatly enriched and improved the public policy research paradigm and further deepened the discussion on theoretical issues.

Multiple Streams Framework (MSF) is a process of policy selection under ambiguity conditions, which is used to explain how policies are made and include the whole process of policy making (Zahariadis, 2014). On the base of extensive and in-depth case studies and empirical research, the framework was scientifically discussed by John W Kingdon, a famous American policy scientist, on the key links in the decision-making process-the setting of agenda and the formation of public policy. Kingdon (1995) applied the dustbin model proposed by Cohen, Marci and Olson to the US federal government, and proposed two "pre-decision" processes: the determination of the agenda and the specific elaboration of options. Kingdon describes how a series of separate problems, solutions and political views come together to put an issue on the public policy agenda that push government to take actions. His research shows that the combination of problems, solutions and political opinions does not occur automatically in American politics (Kingdon \& Stano, 1984).

The framework of MSF is based on bounded rationality and gradualism, and making agenda setting as an independent research content at the system level. Due to ambiguity conditions and the existence of "black box", it is assumed numbers of residual randomness, black box is not static but in the process of continuous evolution, and subtle changes in the external environment may cause complex chemical reactions inside the black box. In the process of carrying out public policy research, the MSF framework characters in generality (which can be used to analyze the policy process of any region at any time) and low entry barriers. In addition, the MSF strongly characters in ability to integrate with theory of Advocacy Coalition Framework, Policy Networks, Punctuated equilibrium Theory and so on. Since its inception, it has been favored by public policy researchers. Various theoretical and empirical discussions on streams have been born at home and abroad. 
However, what's worth discussing is that the proposal of MSF is based on the American federal political system, which has caused substantial discussion of the adaptability. Although many scholars of China try to explain the agenda setting in the Chinese context in the framework of MSF, the differences in political and administrative system bring about differences of constituent elements, evolution environment, development trend in streams of problems, policies and politics. Directly application contributes nothing to the localization of MSF. Therefore, combined with the uniqueness of China's political and administrative system, the paper presents a literature review of MSF in China aiming to discuss the adaptability of MSF in China, and puts forward the mechanism of the three streams under the background of policy structuralized, finally find the law of order in the black box of disorder.

Kingdon applied the original dustbin model to the policy-making process at the national level, but its theoretical framework is based on large number of investigations on health and transportation system in United States. Whether the conclusion is of universal significance has aroused extensive discussion among scholars. This paper uses "multi-streams", "multiplestreams", "policy agenda" and "MSF" as keywords to search the topic in the core magazines of Peking University and Nanjing University. Finally, after removing the irrelevant articles on the topic, this paper selects 135 representative high-level Chinese literatures to review the Chinese research progress of MSF to reflect the research pace of Chinese scholars.

\section{OVERALL}

From the distribution of the literature, we find the focus of scholars' research. Of the 135 Chinese literatures:

- 92 articles focused on universal significance of MSF at the national level in China, such as legislation (7/135), administration (13m/135), social management $(8 \mathrm{~m} / 135)$, education $(34 \mathrm{pm}$ $135)$, social security (6pm 135), medicine and health (3pm 135), food $(2 \mathrm{~m} / 135)$, housing $(2 \mathrm{~m} / 135)$, industry $(3 \mathrm{~m} / 135)$, environmental protection ( $3 \mathrm{pm} \mathrm{135),} \mathrm{etc.} \mathrm{Among} \mathrm{the} \mathrm{articles,} 3$ discuss the local adaptability of MSF with cases, and others are based on post interpretation of specific issues from the perspective of MSF.

- 15 papers focus on local government decisionmaking in China, including public transport price adjustment in Beijing, establishment of Shanghai free trade zone, Entrapment in Shanghai, Grid Inspection System in a certain area of Shanghai, taxi reform in Yiwu, The twovote gender system in Guangshui, cooperation in water pollution prevention and control in Jiangsu and Zhejiang, etc. 8 of them also discussed in depth the problems caused by transplanting MSF to the mainland and how to modify the MSF in Chinese context.

- 8 articles focus on the issues of other countries, which covers US health care reform, the Swedish Innovation Budget Act, the introduction of high-level overseas students in the United States, the open enrollment policy of the City University of New York, the transformation of the defense language in the United States, the early stage of US public policy formulation, ASEAN's climate change policy, the US carbonated beverage tax policy, etc. Five of them are post interpretation of public policy agenda of the US federal and state governments rooted in the American scenario.

- 19 articles focus on the discussion of the MSF framework, involving literature review, the influence of fuzziness, adaptability, and the comparison and integration of MSF with other policy process frameworks, among which, the discussion on adaptability questions the transplantation of the framework in China by comparing the differences of political and administrative systems between China and foreign countries and combining with the local context of China. And put forward some suggestions on how to modify the framework in response to the query.

Scholars pay much attention on post interpretation in framework of MSF. Next, the paper will systematically present the different views of MSF in Chinese context.

\section{POST INTERPRETATION}

This category mainly refers to the literature on interpretations of single case under framework of MSF, with a total of 39 articles, all of which are case studies and accept assumptions and explanatory power of MSF. However, part of studies only discuss the manifestation of the three streams and why the policy window opens, but without discussions on the role of Policy Entrepreneur, Interest Group, Cognitive Community, Think Tank in agenda-setting and the game theory in policy-making process. Chen Chao and Shi Jiangang(2016) discussed the change of the policy of regulation and control of the housing market and the sustainability of the intervention mechanism, although they discussed the influence of interest groups and interest alliances on the formation of political sources, however, it is not clear how to promote the confluence of the three streams and the opening of the policy window as one of the driving forces of policy change. 
When discussing the predicament of villager autonomy and mechanism innovation, Li Yongsheng (2013) mentioned political activists, Gan Jinqiu and Liu Zuyun(2014) discussed government agenda analysis, Jia Ding(2014)discussed mass emergencies and public policy generation mechanism, Wang Bo (2008)discussed the change of management policy for vagrants and beggars, but also failed to clarify how policy entrepreneurs play a role in it. When discussing the extraction of regional spirit, Ren Peng and Chen Jianbing (2016) thought that the discussion activity group and the Liaoning delegation of the two sessions in 2013 had played the role of policy entrepreneurs through mass solicitation and expert discussion, respectively. The spiritual research group is a policy community, which achieves the role of "softening" through the news media.

\section{RESEARCH ON CONCEPT REVISION}

In view of facts that the federal political system of the United States is relatively loose, the decisionmaking of the American government has been influenced by the policy community, policy entrepreneurs and interest groups for a long time. Compared with other western countries, the lobbies in the United States are more active, organized and influential. Therefore, interest groups are important factor in American political ecology, while the power of political parties is gradually weakened. On the other hand, China implements the system of multi-party cooperation and political consultation under the leadership of the Communist Party of China, it is the highest political principle to uphold the leadership of the party in all work. The power of political parties not only has direct decision-making power, but also pays close attention to the voices from all levels of the society. Therefore, to promote the wide use of MSF in our country, scholars have made a conceptual revision to the MSF framework.

Firstly, it is redefinition of the connotation of the streams, especially the connotation and constituent elements of political streams in China's local environment, and recognize the absolute influence of political authority in Chinese policy agenda setting. Zong Hong and Yang Linhong (2014) believe that China's decision-making process continues to follow the upper-level approach to open the policy window. Yu Yongda and Yao Ning (2013) adjusted the connotation of political stream based on the high requirements of policy coherence for the long-term ruling position of the ruling party in our country, replace the "administrative or legislative transition" put forward by Kingdon with "the will of the core leadership", "the adjustment of personnel in key departments" and "national mood" as the connotation of the political streams. It is collectively referred to as "the political orientation of the ruling party" following the integration view of Zahariadis. Ren Peng and Chen Jianbing (2016) integrated the main dimensions of political stream such as "national mood", "pressure groups" and "government change" into "political authority", and believed that "political authority" played a special role in the construction of policy issues in our country. Yu Yongda and Yao Ning (2013) believe that under China's national conditions, the problem stream is a "biased sample" of social problems, and whether social problems can become the stream of problems will be tested by the political stream.

Second, the re-discussion of the mode and mechanism of stream aggregation emphasize the important role of political requirements on stream aggregation, resulting in a series of research frameworks that are more suitable for local conditions of China. Cai Li, Zhang Yue, Zhang Weijie and he Jiangping(2011) adjusted the order of the three streams: Firstly, the change of problem stream led to the change of the public opinion tendency and the polittical will in the "political stream", the party will then entrusts the members of the policy community to update the policy, which leads to the change of the "policy stream". Secondly, they add the role of new media in the evolution of public policy to the model, believing that the role of media as a " mirror" will shorten the time for the convergence of "problem and political streams", and affect the distribution of public opinion and ideology of the authorities. With the same mechanism, when the rulers in "political stream" seek policy suggestions from the policy community in "policy stream", information in problem and political stream will be magnified and distorted by the media, which not only shortens the process of seeking advice, but also affects the integrated application of the framework supplemented by the function of public opinion under the development of new media. Wang Chengyi (2009) proposed that the three streams are not immutable but only as trigger or alternatives waiting for the timing of coupling. On the contrary, because the problem is a complex evolution process, and the formation of the policy agenda also presents the evolution trend of multi-layer stream.

\section{RESEARCH ON FRAMEWORK INTEGRATION}

As described by Paul Kellner and Michael D Jones, few studies discuss the seemingly universal elements of MSF and the relationship between MSF and other theories, even less to provide in-depth exploration. But it is more appropriate that the relationship between these theories should be made clear. The exploration of this connection is precisely the weakness of Chinese MSF-related research.

One of the widely criticized defects of MSF is that it relies too much on accidental factors. Although the 
existence of policy "black box" expands its applicability and explanatory power, however, the state of "organized disorder" can't reveal the further causal mechanism of policy agenda setting and the specific effects produced by various constantly "floating" factors, therefore can't really reveal the whole logic of policy agenda setting. Chinese scholars carried out indepth exploration and research on this issue. Yang Zhijun (2016) embeds 4i elements of policy idea, policy image, key individual and institution into the pre and post decision-making links respectively as intermediary variables, and the purpose of $4 i$ elements as reflective factors in pre-decision-making process of alliance interaction and the post-link embedded in operation of the three streams as belief attributes, is to further open the policy "black box". Find the running logic of variables in the chaotic logic so as to establish the connection between the source and the window of policy. Liu Siyu(2018), Xu Xiaoxin, Zhang Xiulan (2016)and other scholars advocates introducing policy consensus construction into the research on policy agenda setting. Liu Siyu (2018) put forward a nested model of multiple stream model for policy argumentation and consensus construction, which pointed out that only the social problems that reach consensus through policy argumentation attract the attention of the government, whether we can open the policy window and enter the policy agenda depends on the subject participating in the argument and the scale of the consensus reached.

At a time when the power of the Internet and the media is becoming more and more powerful as a medium and platform, the setting of the public policy agenda has been constantly impacted to great extent. Its role as a voice, participation and diffusion platform has greatly enriched people's participation and influence in public policy, and promoted the emergence of more real, smarter and reasonable options. To a large extent, it accelerates or even forces the coupling of the source stream and the opening of the policy window, so the network has become a variable that can't be ignored and has an important impact on agenda setting. There are two views in the academic circles on which link this influence is reflected and how great the influence is. The first point of view emphasizes the absolute influence of the network and media on agenda setting. Zhu Min and Fan Bo (2017) introduce the Schram theory of communication into the MSF to explain the whole process from electronic participation of agenda setting. Liu Ran (2017) starts with the decentralization of the expression of public opinions on the Internet, which explains how the network impacts the Whig phenomenon caused by controlled filtering in the policy agenda setting of our country. Kuang Guangshou and $\mathrm{Hu}$ Ningsheng (2017) verified the influence of the "fourth power" of social media as a public discourse space on the three streams and coupling processes through the Free lunch Program in Poverty-stricken mountainous areas. The scholars represented by Wang Xiangmin and Kong Xiao(2015) advocated media mobilization as the an external input variable driving force of decision-making, and that from the perspective of institutional change, media mobilization is more of a force to break without stand, to criticize than to build, it prepares conditions and constructs environment for institutional change,, and perhaps it can interrupt (or stagnate) a system. However, it cannot form an alternative, nor can it be used as a policy entrepreneur to promote the alternative to reality.

\section{HYPOTHESIS TESTING RESEARCH}

When discussing the policy agenda setting, the MSF should pay attention to that it has certain hypothetical premises, and the ambiguity of hypothetical conditions is also one of the criticisms. However, looking at the description of Kingdonin "Agenda, Alternatives and Public Policy", there are the following assumptions:

- Bounded rationality;

- Time limited of decision makers;

- Ambiguity;

- Stream independence;

- Weak government and decentralization system;

- Contingency.

At the same time, one of the biggest theoretical foundations of Kingdon's MSF is the "organized disorder" of the US federal government, which is specifically uncertain preference, unclear technology and irregular participation. The existence of six hypothetical conditions and three specific attributes constitute the premise of the application of MSF . However, whether these prerequisites are established and whether they need to be modified in different application contexts is also an issue widely concerned by Chinese and foreign scholars in the process of local transplantation. Among them, the most questionable ones are the stream independence and ambiguity hypothesis. Kingdon believes that the development and operation of these three process streams are mainly independent of each other. Whether solutions respond to a problem or not, they can be proposed, and political streams can change suddenly, whether the policy community is willing or not, or whether the problems facing the country have changed. Although Kingdon later supplemented this, he believes that even if the three streams are not completely independent, each stream can still have its own "life".

After applying the MSF to the local context, Chinese scholars agree that the source stream is not independent. Yang Zhijun et al.(2016)proposed that the 
three streams are neither completely independent nor parallel, but one is independent and dependent on each other, and flows successively when discussing the modification of the embedding of the elements of MSF. The dominant streams lead the flow of other streams and converge at the end. Zheng Li (2015) took Beijing's public transport price adjustment policy in 2014 as a case to verify the non-independence of the three streams, arguing that in the process of China's policy, because there is no division between administrative officers and stewards in the administrative system, decision-making and implementation are not two independent systems as a result, and the specific division of administrative functions is often replaced by vertical guidance relations. On the other hand, China's system of integration of discussion and action has also caused the blurring of the boundary between decisionmaking and implementation. Zeng Lingfa (2007) believes that the crux of the problem lies in the actual policy-making process, these three measures are not independent of each other but influence each other, and it's this interaction that makes the whole policy process not completely filled with a haze of chance, on the contrary, it is more purposeful and predictable. Zhu Zhaoxia and Chen Qi (2015) take the establishment process of Shanghai Free Trade Zone as a case to verify that problem stream and policy stream are the premise and basis of public policy formation, and there is interaction between them.

Although the Chinese discussions on the assumptions of stream independence are consistent, they still focus on the expression of views and lack of reasonable basis for support. There are not enough cases or data to show how the three streams interact with each other, and there is a lack of research on this interaction, which is precisely the defect of theoretical hypothesis testing. In his book "Policy process Theory", Zahariadis points out that most of the current hypothesis tests rely on qualitative analysis. Although these studies themselves are meaningful, the quantitative evaluation will make streams analysis more persuasive and predictive. In the second edition of "Agenda, Alternatives and Public Policy", Kingdon acknowledges that these streams are not completely independent or separate from each other, and that they are mainly dominated by different forces, different considerations and different styles. Here, although Chinese scholars agree that there is interaction among the three streams, it is still necessary to introduce Kingdon's discussion on the policy stage in order to take a more in-depth look at the embodiment of the independence of the streams. In fact, in the stage when the policy window is not yet open, the operation of the three streams is relatively independent. Due to the influence of different factors, the three streams can appear independently, and the alternatives can appear before the identification of political activities and problems. Political activities may not necessarily lead to the identification of problems or changes in options, and the identification of problems may not be able to change the options or attract the attention of political forces. At a specific time, after the policy window is opened because of the combination of the three streams, the three streams begin to interact with each other. whether they are political forces within or outside the government, their activities will have a direct impact on the options. While further accurate identification of the problem will undoubtedly have an important impact on the options, and will eventually be able to enter the policy agenda. It is a kind of equilibrium state achieved by interest groups, policy community and other political forces after game, competition and compromise, and it is the result of the formation of policy consensus. At this stage, the three streams can't operate independently, showing an intertwined, complex and changeable dynamic evolution structure, which is also the internal operation process of the policy black box.

\section{LOCAL APPLICATION RESEARCH}

The emergence of the MSF comes from the analysis of how the public policy at the national level enters the government agenda. However, due to the boundary between central and local powers and responsibilities, different powers, financial rights and human rights make the MSF pay special attention to the change of scene in the application. "One of the shortcomings is lack of clear definition of the responsibilities of the central and local governments at different levels and how to divide their policy implications in the two cases. At the local level, what is the relationship between the policy decisions of the government at the local level and the policy orientation of the central government or the government at a higher level? Under the system of decentralization in the United States, there is a certain degree of independence between the state and the federal government. The amendment to the Federal Constitution stipulates that "All powers not conferred on the United States or prohibited by this Constitution shall be retained by the states or the people." But in contrast, in many other countries, the centralization of the central government is obvious, the central government directly interferes with the policy agenda of the local government in the form of administrative instructions, and the local government must first ensure that the administrative instructions of the central government are satisfied. Then it is to carry out local affairs. This makes the importance of the three streams changed in the policy agenda setting of the local government, and the higher the degree of centralization means more important role of the political stream. The coincidence of policy with the ideology of political parties has become a necessary condition for policies to be put on the agenda. In this process, the policy agenda setting of local government is more affected by such 
factors as hierarchical system, department division, authority boundary and so on than at the national level, so the decision-making process is subject to more restrictions. Agenda setting is more complex and changeable.

Among the 15 articles on the application and discussion of local application of MSF , 5 analyzed the characteristics of local government policy agenda setting, including policy pilot, ambiguous governance, selective opening, grass-roots public policy decisionmaking model and so on. Among them, Zhang Haizhu (2016)takes the taxi reform in Yiwu as a case to discuss the policy pilot of the local government, believing that the policy "pilot" as a very flexible policy tool can greatly enhance the prudence of national decisionmaking and reduce the risk of failure on large-scale. Also, the "trial and error" process encouraged by the policy "pilot" is conducive to the emergence of a variety of innovative ideas and actions. Sun Zhijian (2014) put forward a "new streams model" including "agenda stream", "action stream" and "rule stream" to reflect the complexity of local urban governance, and believes that in the situation where the rule of man has not yet succumbed to the rule of law, the choice of policy action often has a strong arbitrariness and contingency. Tang Bin(2018)took the cooperation between Beixian and Alibaba to strongly promote rural Taobao as a case to discuss the characteristic of "selective opening" of the grass-roots policy agenda, and pointed out that the emergence of this "selective opening" is the result of technical adjustments to the agenda-setting process under economic and political pressure, and its intention is not to advocate a new decision-making principle of openness and democracy. Instead, it is to attract a small number of market economy subjects to form the interest binding relationship in the policy process, in order to make up for the policy incompetence or ineffectiveness caused by the resource constraints of the grass-roots government. Taking the policy of "grid inspection" in Shanghai as a case, Rong Zhi(2012) puts forward the realistic model and characteristics of grass-roots public decision-making, and points out that grass-roots public decision-making involves the leading role of the political system and its operation process. It includes bureaucratic institutional factors, policy spillover effects, technological development factors, avoidance of problem definition and think-tank "policy argumentation" participation. Zhu Zhaoxia and Chen Qi (2015), taking the establishment of Shanghai Free Trade Zone as an example, pointed out that political flow plays a leading role in the public policy itinerary, and the use of political strategies is the contributing factor in the formation of public policy.

\section{CONCLUSION}

From the point of view of scholars, the discussion on the policy agenda setting of grass-roots government is not enough, as Zahariadis said, although the method of streams analysis emphasizes the importance of structure, however, the impact of hierarchical structure, governments at all levels and their interactions and specific institutional arrangements have not been systematically studied. At the same time, some scholars directly combine the MSF with the grass-roots public policy, but fail to make it clear whether the MSF based on the national level can better fit the scene of Chinese local government. Some scholars deduce the amendment of the MSF from the policy process of a single local government, which is also a mismatch between the theoretical application basis and the application scenario, so the conclusion is doubtful.

As summarized above, Chinese scholars have no less enthusiasm for the application and discussion of MSF , but due to the change of application scene, the discussion of MSF still needs to be located in the specific institutional environment of China in order to achieve the effective combination of theoretical "soil transplantation" and "local grafting". On the other hand, the Chinese discussion on the MSF pays too much attention to the transplantation of the theory, and there are few hypothesis tests. One of the future directions is the formal test of the assumptions through the quantitative model, and the case of falsifying the assumptions, in order to realize the more in-depth discussion and revision of the hypothesis of the MSF. Finally, how to further clarify the policy black box of MSF and seek rules in the black box also needs to be studied, which will undoubtedly greatly increase the predictability of MSF and make the policy agenda setting process more controllable.

\section{References}

[1] Kingdon, J. W., \& Stano, E. (1984). Agendas, alternatives, and public policies (Vol. 45): Little, Brown Boston.

[2] Zahariadis, N. J. T. o. t. p. p. (2014). Ambiguity and multiple streams. 3(1), 25-59.

[3] Cai li, Zhang Yue, He Jiangping. (2011).Based on Incrementalist: an analysis on public policy process of Mutiplestreams Theory. J. Commercial Times. (31),4-6

[4] Zeng Lingfa. (2007). Policy Stream: a multiple-streams analysis of agenda setting - John W. A Review of Jinden's Policy Theory. J. Journal of theoretical research. (03), 136-139.

[5] Chen Chao, Shi Jiangang. (2016). The change of Regulation and Control Policy and the Sustainability of intervention Mechanism in China's Housing Market - an Analysis based on Multiplestream Framework. J. Journey of Study and practice, 5-12.

[6] Gan Jinqiu, Liu Zuyun. (2014). Analysis of Government agenda from the Perspective of Multiple-streams Theory — taking the Amendment (draft) of the Land Management Law of the people's Republic of China as a case. J. Gansu theoretical Journal. (03), 131-136. 
[7] Jia Ding. (2014). The multiple stream theory and public policies in relation to mass emergencies.J. Journal of Hebei Normal University(Philosophy and Social Sciences Edition). 37(02), 154-160.

[8] Kuang Guangshou, Hu Ningsheng. (2017). Policy Agenda Setting in Social Media Era: An Analysis Based on Kindon's Multiple Streams Flow Theory. J. Social Sciences in Nanjing. (10), 74-80.

[9] Li Yongsheng. (2013). Multi-stream Analysis of the Dilemma of villager Autonomy and Mechanism Innovation in China. J. Rural Economy. (06), 9-13.

[10] Liu Ran. (2017). Discussion on the Mechanism of Policy Agenda Triggered by Network Public Opinion - Query the Multi-Source Model in the Comparison of Three Public Events. J. Theory and Reform. (02), 129-135.

[11] Liu Siyu. (2018). Policy Argumentation and Consensus Building in Multiple Streams Framework - Illustrated by the case of "PM2.5" Event and Air Governance.J. Journal of Gansu Administration Institute. (02), 26-40+126.

[12] Ren Peng, Chen Jianbing. (2016). Review on the Refining Process of Regional Spirit from the Multiple- Stream Framework. J. Journal of Xi'an Jiaotong University(Social Sciences). 36(01), 130-136.

[13] Rong Zhi. (2012). The Model of Multi- sources for Public Decision- making in Grass- roots Units and It's Characteristics. J. Academic Journal of Jinyang. (03), 35-42.

[14] Sun Zhijian. (2014). Why the Model of Ambiguous Governing Has Happened and Became Steady-going within the Practice of the Regulation of Street Vending in Chinese Cities - An Mechanism-based Explanation On the Basis of the NMSM. J. Journal of Gansu Administration Institute. (05), 28-43+11+127128.

[15] Tang Bin. (2018). Demonstration, Stress Reaction and Environmental Adaptation: Using Grouding Theory to Study the Initiation of Rural Policy Piloting. J. Journal of Social Sciences. (07), 19-31.

[16] Wang Bo. (2008). Research on the Transformation of Management Policy of vagrants and beggars from the Perspective of Multi-source flow .J. Forward Position. (01), 171-173.

[17] Wang Chengyi. (2009). From multiple stream to stratified evolution: case from the policy agenda dealing with scientific misconduct in China. J. Studies in Science of Science. 27(10), 1460-1467.

[18] Wang Xiangmin, Kong Xiao. (2015). The Role of Media Mobilization in Institutional Changes: A case study of the Red Cross Society of China since 2011. J. Academic Journal of Jinyang. (04), 114-122.

[19] Xu Xiaoxin, Zhang Xiulan. (2016). Consensus Mechanism and the path of Social Policy agenda setting — taking the New Rural Cooperative Medical system as an example. J. Journal of Tsinghua University(Philosophy and Social Sciences). 31(03), 26-37+191.

[20] Yang Zhijun, Ouyang Wenzhong, Xiao guixiu. (2016). Preliminary Modification on Multiple Streams Model Under the Perspective of Factor-embedded - Based o n Design and Test the Case of "Online Car-hailing Service Reform". J. Journal of Gansu Administration Institute. (03), 66-79+127-128.

[21] Yu Yongda, Yao Ning. (2013). An Exploration of Analytical Framework of Agenda Setting and an Explanation of Institutional Reform of the State Council. J. Chinese Public Administration. (07), 27-31.

[22] Zhang Haizhu. (2016). Multi-stream Analysis of Local Policy agenda setting - A case study of Taxi Reform in Yiwu. J. Journal of Wuhan University of Science and Technology(Social Science Edition). 18(02), 135-141.
[23] Zhao Deyu. (2010). The Logic of Policy making: experience and explanation. Shanghai people's Publishing House.

[24] Zheng Li. (2015). A study on the non-Independence of Policy three sources in China's Policy agenda - taking the Public Transport Price Adjustment Policy of Beijing in 2014 as a case. J. Management Observer. (20), 28-29.

[25] Zhu Zhaoxia, Chen Qi. (2015). The Layered Multiple Streams Theory Centered on Political Stream and Its Application: A Case Study of the Shanghai Free Trade Area. J. Comparative Economic \& Social Systems (06), 68-76.

[26] Zhu Min, Fan Bo. (2017). Research on agenda setting of Network Public opinion Governance. J Administrative Tribune. 24(06), 103-107.

[27] Zong Hong, Yang Linhong. (2014). The Application of the Multiple Streams Theory - Analysis of the Drafting Motivation of the Exit and Entry Administration Law. J Academic Exploration. (10), 75-80. 